\title{
An evaluation of 35 years of leprosy control in Northern Nigeria as demonstrated in the original pilot project Katsina
}

\author{
K WAALDIJK \\ Babbar Ruga Leprosy Hospital, PO Box 5, Katsina, Nigeria
}

\section{Accepted for publication 24 June 1988}

Leprosy control is nothing more and nothing less than trying to interrupt transmission of the disease by first diagnosing and then treating all the active leprosy patients with a sufficient amount of drugs for a sufficiently long time.

Though this seems very easy in theory, it proves to be extremely difficult in practice, and almost none or only very few of the leprosy control projects have achieved this goal.

In Northern Nigeria leprosy control was started in 1952 by Dr C M Ross with the then Katsina Emirate as a pilot project, and by 1960 it belonged to the largest leprosy control projects in the world.

But what it had and still has in quantity, it missed and still misses in quality. Already in 1960 the WHO-LAT survey in Katsina Emirate noted that the recording was very poor and 'absolutely unsuitable for even the most elementary statistics', and it recommended improvement of the recording and that only the leprosy supervisors should make the diagnosis and authorize the registration.

Though an enormous amount of work has been done over the years, basically the same situation exists or it has even become worse. From October 1984 until March 1987 we reviewed all the 185 leprosy clinics in all the 7 local governments of now Katsina State. We found only 2323 real leprosy patients $(8.4 \%)$ among the 27,675 persons registered: no reliable diagnosis, no proper recording, no discipline, no supervision in the field, irregular and insufficient drug supply to patients and clinics and no uniform guidelines. During the 450 clinic visits made we struck 25,352 persons $(91 \cdot 6 \%)$ off the leprosy registers, as we could not detect any sign of leprosy or because they did not attend (some $20 \%$ had fake names?) the visits involved a total drive of $110,000 \mathrm{~km}$.

The total disintegration of the leprosy control and leprosy field work is to be blamed mainly on the non-existence of recording and the complete lack of supervision.

But the strange thing is, there seems to be a tremendous decline in the prevalence of leprosy in Katsina State by at least a factor of 20, in 1951 Dr C M Ross found a prevalence of 39 per thousand, in 1960 the WHO-LAT survey showed a prevalence of 28.7 per thousand, in 1977 the NSL survey noted a prevalence of 3.4 per thousand and in 1987 we come to a calculated prevalence of $1.5-2$ per thousand, all in the same area.

In my opinion this decline is due to the natural course of the leprosy epidemic and to a change in the sociohygienoeconomic conditions in Northern Nigeria, as has occurred in other parts of the world in the past, and is certainly not due to leprosy control, because the quality is too poor.

So, is leprosy in Northern Nigeria under control? Nobody knows, and this question still has to be solved. 
Table 1

\begin{tabular}{|c|c|c|c|c|c|c|c|}
\hline \multirow[b]{2}{*}{ Local government } & \multirow{2}{*}{$\begin{array}{l}\text { Number of } \\
\text { leprosy clinics }\end{array}$} & \multicolumn{3}{|c|}{ Number of registered persons } & \multicolumn{3}{|c|}{ Number of leprosy patients } \\
\hline & & Males & Females & Total & Males & Females & Total \\
\hline Daura & 18 & 656 & 1235 & 1891 & 96 & 61 & 157 \\
\hline Dutsin-Ma & 34 & 1517 & 5094 & 6611 & 144 & 155 & 299 \\
\hline Funtua & 27 & 701 & 1328 & 2029 & 234 & 176 & 410 \\
\hline Kankiya & 30 & 999 & 3356 & 4355 & 193 & 138 & 331 \\
\hline Katsina & 24 & 936 & 3114 & 4050 & 302 & 310 & 612 \\
\hline Malumfashi & 27 & 587 & 2046 & 2633 & 142 & 160 & 302 \\
\hline Mani & 25 & 1276 & 4830 & 6106 & 110 & 102 & 212 \\
\hline $\begin{array}{l}\text { Total Katsina State except } \\
\text { hospital clinic }\end{array}$ & 185 & 6672 & 21003 & 27675 & 1221 & 1102 & 2323 \\
\hline
\end{tabular}

But even with a prevalence rate of $1 \cdot 5-2$ per thousand there are 100,000 to 150,000 leprosy patients in Northern Nigeria, who need some kind of help.

What should be done is the following: First of all we have to review our whole programme and make an inventory of what we have, so that we come to baseline data. Secondly we have to upgrade and improve all the aspects of our project, namely diagnosis, recording, registration, discipline, supervision, administration, transport etc. Last of all, we should think about introducing multiple drug treatment, but only if we have a well organized and well disciplined project.

I would like to stress that MDT in itself is no solution for a disorderly and bad leprosy control project and will do more harm than good.

As leprosy control cannot be done sitting in an easy chair behind a desk, it means that we have to go into the field where the patients and work are to be found. There is nothing heroic about leprosy

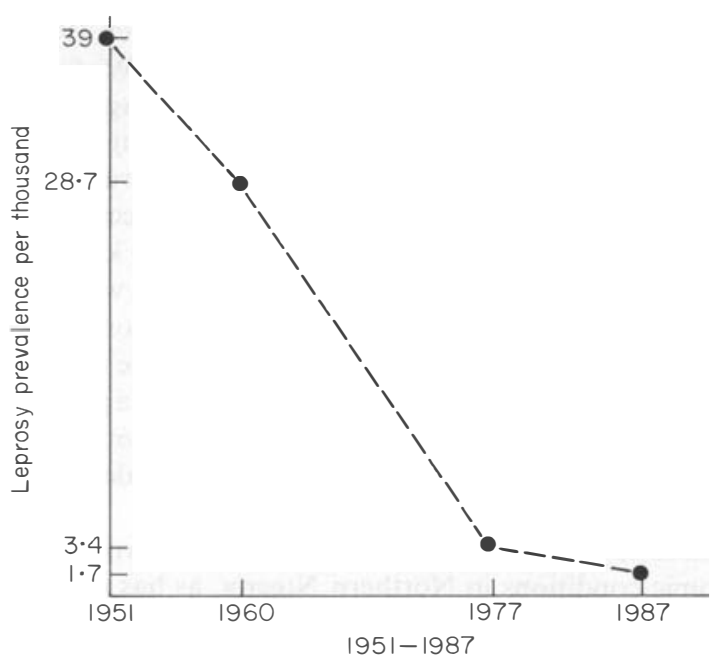

Figure 1 
control, but it can be: tiresome, frustrating, sitting for hours in a car, travelling for kilometers on dangerous and rough roads, suffocating from the heat, sweating profusely, eating sand, inhaling dust, feeling thirsty, seeing sometimes no patient at all and occasionally very boring. However, there is no way out and we have to do it, as only by a continuous effort it just might be possible to control and eradicate leprosy. 